\title{
A Reforma Administrativa no Municipio de Vitória
}

\author{
(Da codificação à Planificação)
}

\author{
Antônio Delorenzo Neto \\ Ex-professor de Legislação Municipal (curso \\ de extensão) da Escola de Sociologia e Po- \\ lítica de São Paulo — Ex-Prefeito Municipal \\ de Guaranésia
}

$\mathrm{T}$

ENHO a honra de encaminhar a Vossa Excelência o ante-projeto do Código Municipal de Vitória, a que fomos incumbido de realizar por autorização de 23 de maio de 1953, devidamente aprovacla pela Câmara Municipal.

Após seis mêses de trabalho pudemos concluir o texto do ante-projeto, que se estende por 1205 artigos, abrangendo as relações jurídicas do Município não reguladas pelo direito comum, desde o regime de posturas até aos regimes tributários e de obras, consubstanciando ainda as normas da planificação municipal. Como subsídio para a elaboração do trabalho, analisamos a documentação da Prefeitura que constou, principalmente, dos seguintes elementos: sinópse do I.B.G.E. sôbre o Município de Vitória, de 1950; mapas do Estado e do Município; legislação básica do Estado (Constituição, Lei de Organização Municipal e Código Tributário); legislação básica do Município (Código de Posturas, Lei n. ${ }^{\circ}$ 276, de 31 de dezembro de 1925; Normas de Processo Fiscal, Lei n. 7 , de 5 de maio de 1936; Código Tributário, Lei n. ${ }^{\circ} 173$, de 19 de dezembro de 1950); Leis orçamentárias; e, diversos textos esparsos que interessavam direta, ou indiretamente, ao seu desenvolvimento.

Depois de demorado exame dessa legislação, estabelecemos o esquema do Código, submetendo-o tanto quanto possível a rigorosa metodologia, classificando cuidadosamente as matérias tendo em vista sua generalidade decrescente e complexidade crescente. A fim de conseguir êste objetivo, nos beneficiamos de esquemas que havíamos concebido anteriormente para os municípios de Guaranésia e Ourinhos. Vencida a primeira etapa, o seu texto provisório foi levado ao conhecimento de V. Ex:ia., para exame e discussão. A seguir, outros elementos foram trazidos à Codificação, a fim de ser ampliada a sua base técnica. Entre êsses elementos, cumpre destacar o ante-projeto de Código de Obras, elaborado em 1952, para o Município de Vitória pela "Em-

(*) Exposição de motivos apresentada ao Prefeito de Vitória (Espírito Santo), Dr. Armando Duarte Rabelo, por ocasião da entreğa do Projeto de Código Municipal, em 20 de novembro de 1953. 
prêsa de Topografia, Urbanismo e Cunstruções Ltda.", do Rio de Janeiro, cujo texto sofreu na oportunidade, vigorasa apreciação da parte da "equipe" da Prefeitura.

De posse dos novos elementos, empreendemos um reexame crítico e seleção de todos os artigos já elaborados, e reclassificamos em caráter definitivo, a matéria. Se nem tôdas as sugestões foram acolhidas de nossa parte, fôrça é reconhecer que decisivamente contribuiram a enriquecer o conteúdo do Código, permitindo alargar as dimensões do sistema, e aumentar o poder das suas normas. Em face dos materiais que compõe o seu articulado, o Código Municipal de Vitória apresenta um sentido casuista. Aliás, neste particular podemos surpreender um traço de diferenciação entre a codificação do direito municipal e a do direito comum. A configuração dos atos da vida local, sôbre os quais se aplica o poder regulamentar, se caracterisa pela multiplicidade de casos que se particularizam a cada passo, de sorte que, a legislação que os pretenda regrar, há de sofrer uma adaptação tal que lhes seja instrumento a garantir tôda proteção, afastando as possibilidades de falsas interpretações, motivo tantas vêses da decadência do Govêrno Municipal, que desce assim a cometer incoerências e ilegalidades, confundindo o pessoal e o impessoal, a justiça e a injustiça. Na técnica do direito comum já se pode prescindir do caso concreto, e subir de análise à síntese, porquanto, a esfera das relações jurídicas assume um caráter geral. Nas dúvidas e controvérsias, o apêlo que o julgador faz à analogia, à jurisprudência, à doutrina e aos princípios gerais do direito, permite-lhe extraordinária segurança nas decisões. No campo do direito local êsses recursos não pcdem ser utilizados com semelhante eficácia, porque o pormenor e a análise dominam o equacionamento das relações jurídicas. Fugir ao reconhecimento dêsses peculiares da atividade do Município, será contribuir para uma orientação abstrata que contraria a sua verdadeira vocação institucional no quadro da Federação, como intermediário entre os Estados autônomos e a União soberana. O grande esfôrço de sistematização legislativa, que se empreendeu com o Código de Vitória, significa, também, o reconhecimento de uma orientação moderna na compreensão dos fenômenos jurídicos, fazendo-os depender dos fenômenos sociais, que sôbre êles exercem uma ação determinadora. Entender o contrário, será caminhar na mais nefasta abstração, convertendo o direito num instrumento de injustiça e atraso social, indiferente ao rumor das refórmas e reivindicações que tão profundamente agitam a consciência do nosso tempo. O jurista Roscoe Pound, colocou em têrmos lúcidos o problema, ao proclamar a necessidade inadiável, em benefício da organização jurídica dos povos, de combatermos o apriorismo e a superficialidade com que se constroem as leis ou sistemas de leis, tão distanciados das realidades sociais. Assim resumiu êle as características do pensamento jurídico contemporâneo: (1)

I - uma atitude funcional;

(1) "in" La sociologie au XXème Siècle - Paris, 1947, tome Ier p. 349. 
II - um estudo do direito nas suas relações com o conjunto do contrôle social;

III - um movimento no sentido da justiça preventiva;

IV - um movimento no sentido da individualização e da particularização;

$\mathrm{V}$ - um movimento no sentido de uma cooperação cada vez mais estreita com tôdas as ciências sociais;

VI - um estudo dos limites da eficácia da ação legal.

Ainda cumpre assinalar que na elaboração do Código, do texto provisório ao texto definitivo, preferimos eliminar dêle tôdas as definições que envolvessem a conceituação jurídica pròpriamente dita, apenas, mantendo aquelas que pudessem elucidar matéria de natureza técnica. Esta orientação, aconselhada pela experiência da codificação em outros setores do direito melhor satisfez às necessidades práticas da aplicação da lei. Tôdas as normas que, nas leis anteriores do Município, no texto provisório do ante-projeto, ou nas interpolações posteriores, pudessem, do ponto de vista das exigências da equidade e da justiça, traduzir-se em dubiedade ou abuso, foram rejeitadas em benefício da coerência do sistema da codificação. As matérias que exigem a prova da experiência, como por exemplo, a reestruturação dos serviços administrativos, e o Estatuto dos funcionários, serão objeto de leis especiais. O que, porém, assinala profundamente o novo Código de Vitória, são as disposições sôbre a planificação municipal. Nêste passo, se demonstra de maneira insofismável, a importância da codificaão, que atua além dos limites estritamente jurídicos, para modificar e transformar profundamente os métodos de administração. A produtividade dos serviços públicos, está na dependência da codificação. Confirmando êsse nosso ponto de vista, aí está a lição de ARDANT, (2) na mais recente monografia sôbre a técnica do Estado:

"Ce serait une erreur de croire que la codification ne présente d'interêt que pour les juristes. L'histoire même devrait nous mettre em garde contre cette opinion. Les grande travaux de codification sont presque tous situés, aux tournants de l'histoire aux débuts de l'Etat romain, vers la fin du Monde Antique, au début de la Renaissance, au commencement de la Monarchie absolue, á la fin de la Révolution. Il doit donc y avoir quelques rapports entre cette technique juridique et les mouvements les plus profunds qui affectent la vie en societé."

Recordemos os resultados obtidos pela Prefeitura de Ourinhos (Estado de São Paulo), em conseqüência da reforma jurídica — administrativa ali

(2) Ardant, Gabriel Technique de L'Etat - Paris, 1953, pp. 91-104. 
empreendida, em 1952. E' o que se pode observar nêste quadro comparativo de receitas ali arrecadadas, antes e depois da codificação:

\section{ORÇAMENTOS MUNICIPAIS}

\begin{tabular}{c|c|c|c|c|c}
\hline \multicolumn{3}{c|}{ ANTES DA CODIFICAÇ̃̃o } & \multicolumn{2}{c}{ DEPOIS DA CODificaç̃̃o } \\
\hline 1949 & 1950 & 1951 & 1952 & 1953 & 1954 \\
\hline Cr\$ & Cr\$ & Cr\$ & Cr\$ & Cr\$ & Cr\$ \\
3.581 .700$, & $4.321 .000,00$ & $4.350 .000,00$ & $4.687 .600,00$ & $9.630 .000,00$ & $12.907 .000,00$ \\
\hline
\end{tabular}

Os estudos então levados a eftito - agora confirmados pela experiência - propiciaram um desenvolvimento à administração jamais atingido, que encontre sua base na implantação de três técnicas conjugadas:

$\left.1 .^{\circ}\right)$ a técnica da codificação;

$\left.2 .^{\circ}\right)$ a técnica da tributação racionalizada;

3. ${ }^{\circ}$ ) a técnica da planificação.

Os dados comparativos que citamos, evidenciam um impressionante resultado de crescimento de receita, pois, a soma dos excessos nos dois últimos orçamentos quase equivalem à soma total dos quatro anteriores! $\mathrm{E}$, em conseqüência, os problemas do Município de Ourinhos foram equacionados dentro de um quadro lógico, sob a garantia de uma vigorosa base jurídica e financeira.

Dêsses benefícios oriundos de um esfôrço de racionalização e conjuntura, é que estava a reclamar a administração municipal de Vitória, onde as responsabilidades são muito maiores, considerando as funções de cidade, enquanto capital do Estado, e enquanto centro urbano com população efetiva superior a 100.000 habitantes. Para verificar-se como, até o presente, era lento o crescimento dos seus recursos, atentemos nos dados seguintes:

RECEITA ARRECADADA EM CR $\$ 1.000,0$

(Total geral)

\begin{tabular}{c|c|c|c}
\hline 1945 & 1946 & 1947 & 1948 \\
\hline 6.177 & 6.830 & 8.845 & 8.272 \\
\hline
\end{tabular}


Observados os três últimos exercícios, veremos que permanece a mesma situação:

RECEITA ORÇADA

\begin{tabular}{c|c|c}
\hline 1951 & 1952 & 1953 \\
\hline Cr\$ & Cr\$ & Cr\$ \\
$15.000 .000,00$ & $19.000 .000,00$ & $22.305 .000,00$ \\
\hline
\end{tabular}

O desajustamento econômico que vem sofrendo o país não influiu, a rigor, nas atividades de Vitória; os últimos dados comparativos publicados, indicam a sua privilegiada situação no que concerne ao mais importante fator de sua economia - o café, cujo volume de exportação baixou, sensivelmente, em 5, das 7 cidades comparadas. Eis o resumo estatístico: (3)

\section{JULHO A SETEMBRO}

(EM SACAS)

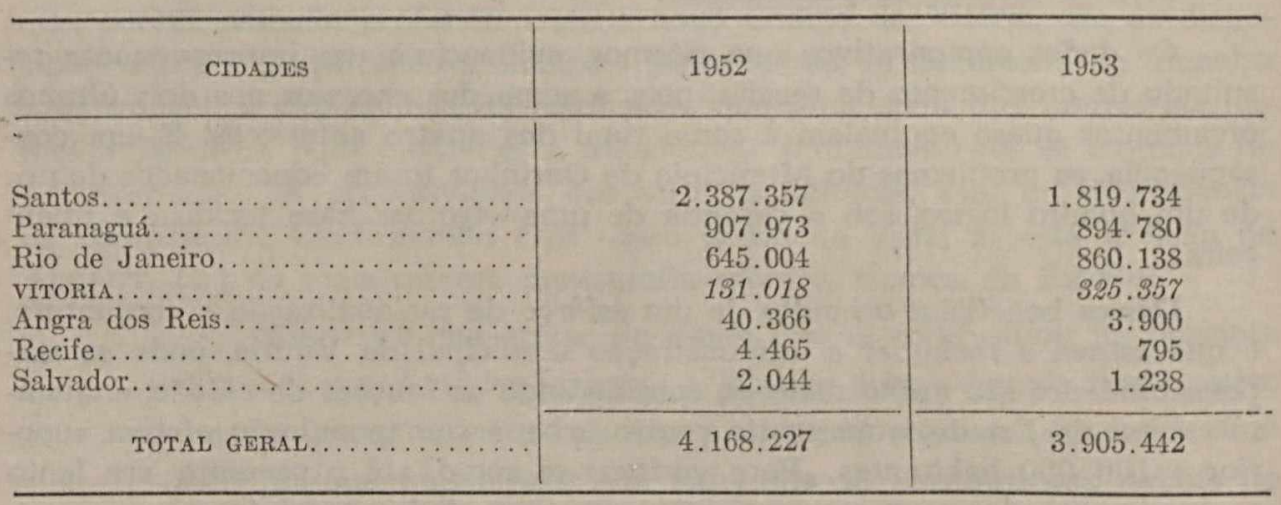

(3) "in" Diário de São Paulo - 25 de outubro 1953.

Contrastando com a situação econômico-financeira em que se encontra - Município, os dados e conclusões acolhidos na introdução ao Ante-projeto do Plano Municipal de Obras e Empreendimentos, demonstram insofismàvelmente que Vitória é a cidade onde a população apresenta o mais elevado índice de capacidade contributiva, superando-o apenas, o Município de São Paulo. Dêsse notável trabalho, vale a pena transcrever o tópico 42 , (4) onde

(4) Plano Municipal de Obras e Empreendimentos - Vitória, 1953, pp. 22-24. 
com clareza se configuram as verdadeiras possibilidades do Município, comparativamente às demais capitais do País:

"Outro método para avaliar o grau de eficiência de um sistema tributário consiste em conhecer o índice de contribuição percapita da população, através da relação existente entre a receita arrecadada e a população. Esse índice, por si só, pouco significará se não se levar em conta a capacidade contributiva da população. Nos estudos que aqui fazemos, para aferir essa capacidade, temos nos valido, sempre, do movimento do giro comercial, que, conforme já dissemos, representa o movimento de venda de mercadorias, elemento mais representativo da riqueza em circulação. Isso quer dizer que, determinando-se, pura e simplesmente, o índice aritmético, com base na receita arrecadada e na população, deixando-se de levar em conta a capacidade contributiva, desta, chegaremos, sem dúvida, a falsas conclusões. Vejamos um exemplo de que acabamos de dizer. Os índices de arrecadação percapita, de Vitória e Belém do Pará são, respectivamente, de $\operatorname{Cr} \$ 221,65$ e $\operatorname{Cr} \$ 105,27$. A primeira vista parece que 0 habitante de Vitória paga duas vêzes mais impôsto do que $\supset$ de Belém. Todavia, sendo respectivamente, de $\operatorname{Cr} \$ 44.600$ e $\operatorname{Cr} \$ 8.950$, o giro comercial por habitante ano, de Vitória e Belém, pode-se concluir que, enquanto a contribuição de cada habitante de Vitória representa $0,49 \%$ do movimento do giro comercial percapita, ja a de Belém corresponde a $1,17 \%$. Fica demonstrado, assim que, considerada a capacidade contributiva, cada habitante de Vitória paga muito menos impôsto do que cada habitante de Belém, sendo, mesmo, o que menos impôsto paga entre os habitantes das capitais brasileiras. Para documentar, melhor, as considerações que vimos de desenvolver, resolvemos ilustrá-las elaborando uma tabela procurando demonstrar quanto teria de pagar cada habitante das capitais brasileiras se sua contribuição fôsse aferida tendo por base a contribuição de cada habitante de Vitória, apurada segundo a capacidade contributiva expressa pelo giro comercial por habitante-ano. Os resultados são os seguintes:
1. $\left.{ }^{\circ}\right)$ Niterói
906,11

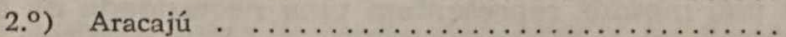
833,20

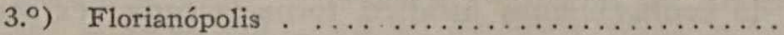
674,43

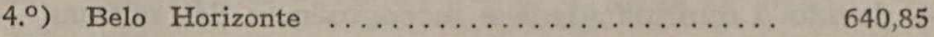

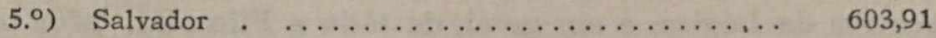

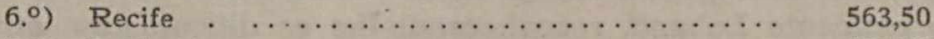

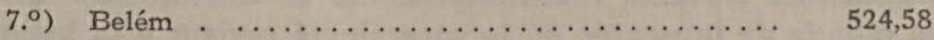

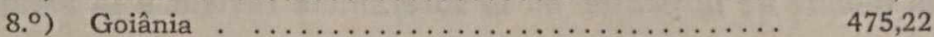

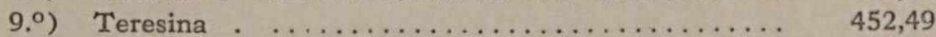
10) São Paulo ......................... 440,10

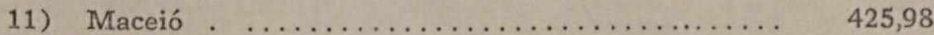

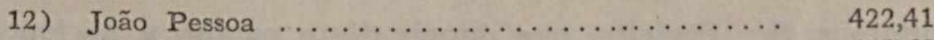

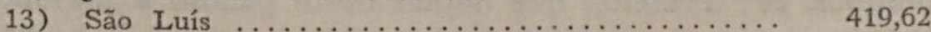

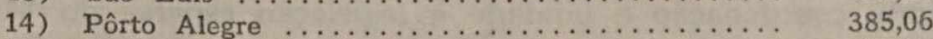
15) Fortaleza . . . . . . . . . . . . . . . . . . . . 373,32

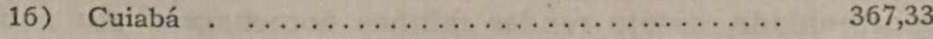


17) Natal . . . . . . . . . . . .

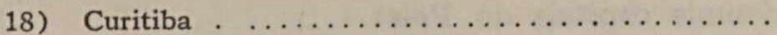

Enfim, do cofronto estabelecido, é persuasiva a conclusão de que o $\mathrm{Mu}$. nicípio de Vitória é aquele onde é mais baixa a contribuição da população, em têrmos de tributação municipal.

Portanto, as condições do município revelaram sua aptidão para a ampla reforma programada, que leva, no que toca à receita, a um orçamento de Cr\$39.747.000,00, em 1954. Entre os recursos que respondem por essa transformação, cabe à Contribuição de Melhoria a sua maior parte, num total de Cr\$9.748.000,00. Podemos afirmar, sem temer engano, que a Contribuição de Melhoria, nas bases jurídico-administrativas, em que foi utilizada no projeto do Código Municipal, dará a Vitória a primazia entre as cidades brasileiras, na aplicação do importante recurso após a vigência de lei federal respectiva, (Lei n. ${ }^{\circ} 854$, de 10 de outubro de 1949).

Vamos referir, em síntese, às grandes linhas que caracterizam o Código. De acôrdo com o que já dissemos anteriormente, subordinamos a metodologia do sistema, ao princípio que estabelece a classificação das normas de acôrdo com a sua generalidade decrescente e especialização e complexidade crescentes. Em conseqüência, duas grandes divisões foram necessárias, em Parte Geral e Especial. Ambas se sub-dividem em Livros que compreendem, em cada um dêles, tôdas as matérias afins de um determinado assunto. Cada Livro comporta desmembramento em Títulos, que agrupam disposições sôbre os assuntos na medida em que se particularizam. Os Títulos, por sua vez se desmembram em Capítulos, seções e sub-seções conforme seja necessário fazêlo, por razões de método, sempre procurando com clareza ajuntar e distinguir as respectivas noções e normas. Todo o articulado da Parte Geral é precedido por Disposições Preliminares, contando apenas sete artigos, e que por assim dizer presidem a orientação que domina a inteligência de todo o texto. $\mathrm{O}$ esquema em anexo, elucida êsse ordenamento legal em todos os seus diversos elementos. O que mais assinala um trabalho dessa natureza é o tratamento lógico, que tem sido, aliás, objetivo dos codificadores, desde os juristas romanos. Os métodos lógicos, evidentemente, são uma condição inelutável de progresso, e por isso mesmo, representam uma necessidade de ordem prática. E, no campo do conhecimento jurídico, torna-se cada vez mais imprescindível - devido à multiplicidade e incongruência das normas - a utilização dos recursos da Lógica, e em geral, de tôda a Filosofia. Meditando sôbre o tema, o eminente Laband, reconhecendo-lhe as dificuldades, afirmou: "Le Noit est un monde de la pensée où la suzeraineté revient à la logique."

$$
\text { *) * * }
$$

Acreditamos, Sr. Prefeito, que depois dêste penoso e paciente trabalho, que imprimiu coordenação e unidade à legislação esparsa do Município, a colenda Câmara Municipal poderá apreciá-lo e examiná-lo em breve prazo. $\mathrm{E}$, nesta oportunidade, desejo render minhas homenagens aos nobres Verea- 
dores, que com tanto entusiasmo e civismo se associam à obra de recuperação administrativa empreendida por V. Excia.

Antes de concluir, ao reiterar-lhe as expressões de sincero aprêço e agradecimento, desejo ainda manifestar minha profunda admiração pela inestimável colaboração pessoal de V. Excia., no debate dos assuntos estudados, como também à dedicada atuação dos ilustres Diretores de Departamento da Prefeitura.

Por tudo isso, por êsse esfôrço coletivo, à tarefa que empreendemos de apurar o direito municipal brasileiro, se acrescenta um subsídio de grande valia, pois a experiência que para logo principiará em Vitória, demonstrará, sem dúvida, que a vida está sempre a criar novos direitos, e que a codificação é o instrumento capaz de fixá-los, no meio onde a vida nos é mais cara, porque na Cidade, isto é, no meio em que habitamos, e exercemos todos os atributos inerentes à nossa vocação política. Eis as razões que justificam o Código Municipal, que há de ser a lei suprema da Cidade, dir-se-ia o "Jus proprium civitatis", pressentido nos Institutos de Gáio (5) e realizado no Direito moderno.

A construção da cidade universitária determinará uma radical mudança no ensino superior do país, tradicionalmente fragmentário e individualista. Os velhos e inadequados edifícios que abrigam as nossas Faculdades serão substituídos pelos amplos e modernos conjuntos da ilha Universitária, resultado da ligação de nove pequenas ilhas situadas na baía de Guanabara.

Seria desnecessário acentuar que a cidade universitária dará ao estudante o espírito de classe que, infelizmente, até hoje, não sentimos no país, justamente em virtude da dispersão dos centros educacionais.

Arthur Seixas - Cidades Universitárias, In "Revista do Serviço Público" - página 106 - Volume I - n. 3, Março de 1954.

(5) Instit., 1, 2, 1. 